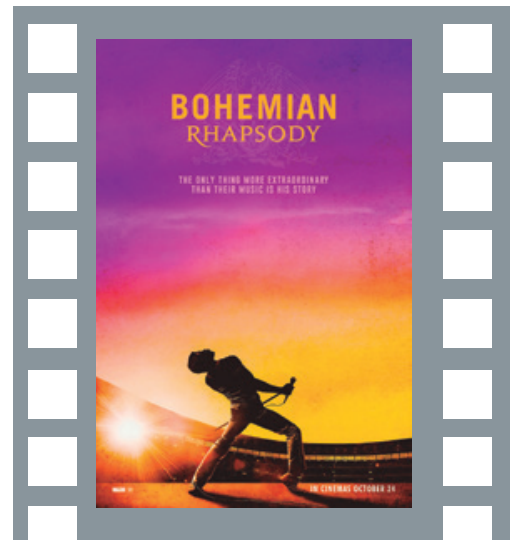

Título original: Bohemian Rhapsody

Nacionalidad: Reino Unido

Dirección: Bryan Singer

Guion: Anthony McCarten (historia: Anthony McCarten, Peter Morgan)

Productora: Coproducción Reino Unido-Estados Unidos; GK Films / New Regency Pictures / Queen Films Ltd. / Tribeca Productions / Regency Enterprises. Distribuida por $20^{\text {th }}$ Century Fox

Año: 2018

Interpretación: Rami Malek (Freddie Mercury); Adam Rauf (Freddie Mercury de joven): Gwilym Lee (Brian May, guitarrista de Queen); Ben Hardy (Roger Taylor, baterista de Queen); Joseph Mazello (John Deacon, bajista de Queen); Lucy Boynton (Mary Austin, pareja de Queen); Aidan Gillen (John Reid, segundo mánager de Queen); Tom Hollander (Jim Beach, tercer manager de Queen); Allen Lech (Paul Prenter, mánager persona de Mercury): Aaron McCusker (Jim Hutton, pareja de Mercury): Meneka Das (Jer Bulsara, madre de Mercury); Priya Blackburn (Kashmira Bulsara hermana de Mercury); Max Bennett (David, nuevo novio de Mary Austin)

Música: John Ottman (canciones: Queen)

Fotografía: Newton Thomas Sigel

Género: biografía, drama, música

Duración: 129 minutos

Premios: 2019: 4 Premios Oscar: mejor actor (Rami Maleck): mejor montaje; mejor edición de sonido y mejor sonido; 2 Globos de Oro: mejor película drama y actor (Rami Malek); 2 Premios BAFTA: mejor actor (Rami Malek) y sonido. 7 nominaciones; Critics Choice Awards: nominada a mejor actor, vestuario y maquillaje; Asociación de Críticos de Chicago: nominada a mejor actor (Rami Malek): Satellite Awards: nominada a mejor actor comedia/musical (Rami Malek); Sindicato de Productores (PGA): nominada a mejor película; Sindicato de Actores (SAG): mejor actor (Rami Malek), nominada mejor reparto; Premios David di Donatello: nominada a mejor filme extranjero.

Trailer: https://www.youtube.com/watch?v=E2V5unHEznA

\title{
Bohemian Rhapsody
}

parece que he creado un monstruo. Cuando estoy actuando soy extrovertido, aunque en el interior soy completamente diferente.

Freddie Mercury

\section{Mónica Muñoz Sobrino}

y Carmen Pereira Domínguez

munozsobrino@edu.xunta.esy mcdguez@uvigo.es

\section{La historia}

Es el momento en que la banda Queen inicia su intervención en el memorable concierto de rock Live Aid para combatir el hambre en Etiopía, celebrado el 13 de julio de 1985, en el estadio Wembley de Londres; recital considerado como el mejor hasta la fecha y la actuación de Queen, con un Mercury glorioso, ante un espléndido escenario, calificada como la actuación más brillante de la historia del rock. Un flashback nos remonta a los orígenes del grupo y nos guía por la trayectoria vital de su líder, Freddie Mercury.

Como dicen los protagonistas, Queen es un grupo de inadaptados que toca para inadaptados. Pero también es la familia que apoya incondicionalmente, sin juzgar, y que alienta la creatividad liberadora de sus miembros. A través de la música de Queen reviviremos las luces y las sombras de las décadas de 1970 y 1980, y entenderemos las circunstancias sociales que fraguaron el "mejor grupo británico de todos los tiempos" (título otorgado tras un sondeo realizado por la emisora BBC Radio 2 en 2007).

\section{Temas}

Crecimiento personal

Drogadicción

Educación familiar

Educación musical

Hambruna en África: Live Aid

Identidad sexual

Inadaptación social

Influencia de medios de

comunicación y tecnologías de la

información

Trabajo en equipo

SIDA

\section{Valores}

\section{Amistad \\ Confianza \\ Creatividad}

Entereza ante la enfermedad y la muerte

Éxito

Fidelidad y perdón

Respeto

Satisfacción de la entrega a los demás

Tenacidad y seguridad en sí mismos

Tolerancia

\section{(r.) Antes de ver la película}

1. Indagamos sobre la música rock. Los años 50 (con Elvis Presley, el "rey del rock") se considera la época dorada del rock. Pero este estilo surge al fusionarse otros de diversas procedencias: investiga sobre ellos.

2. Después de la época dorada surgieron múltiples tendencias en el rock. Organiza en un mapa mental las principales, señalando a sus representantes más destacados.

3. Todos los grupos de rock coinciden en que utilizan tres instrumentos, a los que se les puede añadir teclado o piano. ¿Cuáles son esos instrumentos? Después de identificarlos y clasificarlos según su familia instrumental, haz un esquema con las partes más destacadas del instrumento. Podrías también explicar su evolución o génesis a partir de otros instrumentos preexistentes.

4. Busca información sobre películas dedicadas a grupos de música rock https://culturacolectiva.com/cine/peliculas-para-los-amantes-del-rock
5. En una encuesta llevada a cabo en el año 2007, los oyentes británicos consideraron a Queen el mejor grupo británico de todos los tiempos. Investiga sobre los miembros que integraban la banda y sus funciones en el grupo. Conoce su discografía.

6. En 1985 Bob Geldof (cantante, compositor, actor y activista político irlandés) lideró una iniciativa solidaria para erradicar la hambruna que afectaba a los países del África Oriental, especialmente a Etiopía y Somalia. Averigua qué fue el movimiento Live Aid y los conciertos celebrados en Europa y América.

7. En los años 80 apareció una nueva enfermedad con prevalencia en la comunidad homosexual: el SIDA. El desconocimiento de esta afección y sus causas provocó situaciones de aislamiento entre las personas que la padecían. Busca información sobre los síntomas y el modo de contagio de la enfermedad. Asimismo, sobre su origen, evolución y estado actual. 


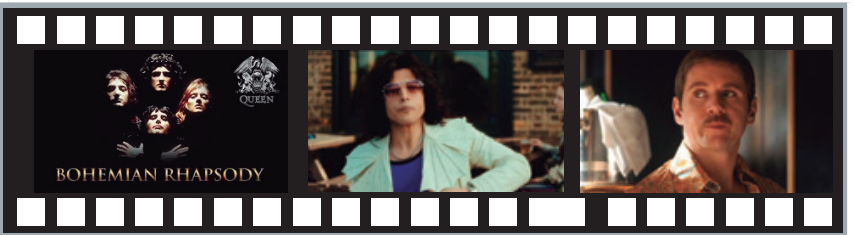

1.1. Queen tiene una entrevista con dos representantes de una productora en una terraza (00:19:44 - 00:20:47). Los demás miembros de la banda ya están sentados, cuando Freddie llega ataviado de una manera peculiar.

En aquella época se utilizaba un tipo de vocabulario que hoy resulta políticamente incorrecto. En este caso, hace referencia a la orientación sexual de las personas.

También en otra secuencia veíamos cómo un término despectivo se refería al origen de Freddie.

1.2. El productor pregunta: "¿Qué tiene Queen que le gusta a todo el mundo?". Bryan contesta inmediatamente: "Somos cuatro inadaptados que no pegamos y que tocamos para los inadaptados" (00:20:48 - 00:21:15)

Por primera vez se alude al hecho de que Queen es una familia, una expresión que se repite muchas veces a lo largo de la película (00:21:14).

1.3. Las miradas, a veces, también hablan. Por primera vez aparece Paul, el futuro mánager de Queen (00:33:41 - 00:35:51).

1.1. ¿Cómo describirías su indumentaria? ¿Se detectan prejuicios sociales?

¿Qué impresión reciben los demás miembros de la banda? ¿Cómo perciben a Freddie?

Reflexiona sobre la importancia de que el idioma no segregue a las personas por sus creencias, opiniones, origen, sexo u orientación sexual. En la actualidad, ¿piensas que este tema se ha superado? Justifica la respuesta.

1.2. ¿En qué se puede reflejar la inadaptación a la que hace referencia Bryan? Describe a cada miembro de la banda: sus inicios, aficiones, estudios realizados, funciones desempeñadas en el grupo, vidas personales y familiares.

Piensa sobre lo que puede significar la afirmación de que son una familia ¿qué sabes de la vida en familia del grupo?, ¿cómo se comportan con sus hijos?, ¿fomentan el diálogo y la comprensión?

1.3. ¿Describe qué te sugiere su mirada? ¿Cómo va influyendo esta persona en el grupo?, ¿y en Freddie?

\section{Una noche en la ópera}

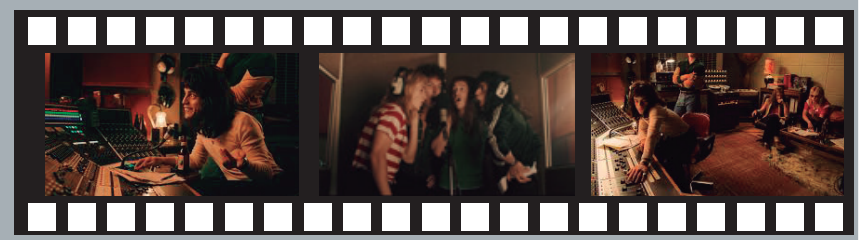

2.1. De regreso de la promoción de su primer disco, Queen se embarca en su segundo proyecto que decide titular Una noche en la ópera. Sin embargo, su productor está en desacuerdo con el disco, ya que pretende repetir la fórmula del disco anterior. https://www.youtube.com/

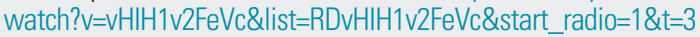

2.2. Para reafirmarse en su opinión, el productor dice: "a nadie le gusta la ópera". Freddie sentencia: "Oueremos hacer un disco de rock con la grandeza de la ópera". Y Miami apoya: "a mí me gusta la ópera". En otras secuencias de la película vemos a Freddie escuchando ópera (00:29:49 - 00:32:07).

2.3. Otro punto de fricción es el sencillo con que se promocionará el disco. El grupo decide que sea Bohemian Rhapsody. El productor se niega rotundamente por la longitud del tema. Sin embargo, la banda se mantiene y busca soluciones alternativas. Parece que Queen tiene las ideas claras: no admite opiniones contrarias a las suyas (00:37:22 - 00:45:17).

2.4. Una noche en la ópera es también el título de una famosa película de los Hermanos Marx (Sam Wood, Estados Unidos, 1935). Además de pretender ser un homenaje a la ópera.

2.1. Reflexiona sobre el hecho artístico. ¿Crees que un artista que se repite constantemente 0 que reitera fórmulas de éxito puede perdurar en el tiempo? Escucha los sencillos que componen el disco Una noche en la ópera. ¿Crees que podríamos clasificarlos todos dentro de la misma categoría?

2.2. ¿Ves en las piezas que has escuchado del álbum alguna influencia de la ópera? Reflexiona sobre el mestizaje de estilos musicales. ¿Crees que es una manera de progresar y hacer cosas nuevas 0 , por el contrario, debemos defender el purismo de las formas?

2.3. ¿Cómo nos pueden condicionar las imposiciones? ¿Y las normas? ¿Crees que esta es una postura inteligente en la vida o habría que matizarla? ¿Qué papel juegan la creatividad y la innovación en estas situaciones? Describe cuáles son las finalidades del promotor y las de la banda. Mencury, F. (2007). Freddie Mercury: su vida contada por él mismo. Barcelona: Robinbook, Ediciones

2.4. ¿En qué medida crees que este álbum puede ser, también, un homenaje a esta obra maestra del cine? ¿Qué similitudes encuentras?

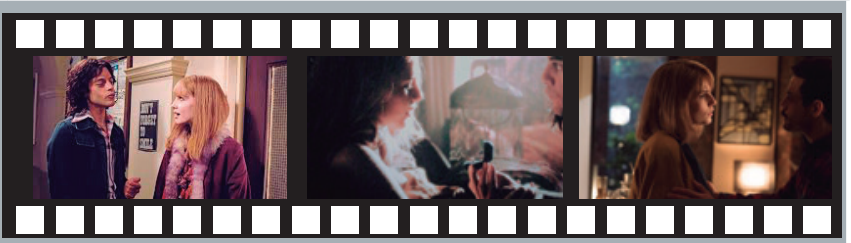

3.1. Freddie está con Mary. Esta le pregunta qué siente en el escenario. Él contesta: "Cuando sé que me escuchan ni, aunque quisiera, podría desafinar. Soy la persona que debía ser. No tengo miedo. Solo lo siento en el escenario y cuando estoy contigo" (00:23:21 - 00:23:52).

3.1. Hay personas que se transforman en el escenario. Que son auténticos artistas. Y se les perdonan todas sus extravagancias, precisamente, porque son de otra pasta: son artistas. ¿Crees que existen personas así? ¿Piensas que Freddie es una de ellas? ¿Qué cambios se evidencian? 
3.2. Freddie entrega a Mary un anillo. "Eres el amor de mi vida", le dice. Y añade: "Prométeme que nunca te lo quitarás, pase lo que pase". "Juntos llegaremos muy lejos". Mary fue para Mercury su gran apoyo e inspiración. Ella estuvo muy pendiente de toda su andadura vital (00:23:59-00:25:26)

3.3. Poco después de esta declaración de amor hacia Mary, encontramos a Freddie hablando por teléfono con ella desde una cabina en Estados Unidos. Un camionero entra en el servicio de hombres y lanza una mirada a Freddie. Tras colgar, él se queda pensativo, mirando la puerta del baño (00:27:36 - 00:28:25).
3.2. A lo largo de toda la película se pone de manifiesto que la relación entre Mary y Freddie es muy especial. Existe entre ellos un auténtico vínculo de fidelidad. Dada la vida que más adelante decide vivir Freddie, ¿es fácilmente comprensible la reacción de Mary? ¿Crees que la vida de Freddie (y por extensión, la de Queen) habría sido igual de no haber existido Mary?

3.3. ¿Qué pensamientos crees que pasan por su cabeza? ¿Qué sentimientos le surgen? ¿Tiene todo claro o está sufriendo una lucha interior? Freddie decía de Mary: "Para mí, fue un matrimonio. Creemos el uno en el otro. Todos mis amantes me han preguntado por qué no podrían reemplazar a Mary. Es porque es sencillamente imposible". https://elpais.com/elpais/2018/11/12/ album/1542017865_474395.htm|\#foto_gal

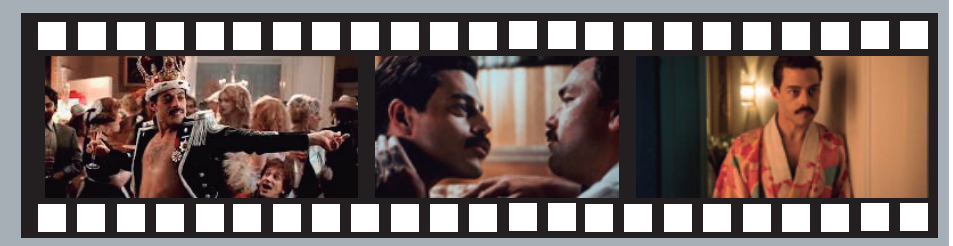

4.1. Aleccionado por Paul, Freddie decide separarse de Queen. Inicia una vida de extravagancias y excesos, aleccionado por su mánager-amante, quien intenta separarlo de sus verdaderas amistades. Freddie se compra una casa enorme, pero se siente solo, a pesar de poseer docenas de gatos (00:54:45 - 00:55:39).

Freddie ofrece una fiesta e invita a los miembros de Queen, que se sienten incómodos y hacen comentarios del tipo: "Perteneces a una banda de rock, no a Village People". "Cada vez te pareces más a Paul". "Ya tienes a tu mascota". A lo que Freddie responde: "Es leal. La lealtad es importante" (00:57:30 - 00:59:47)

4.2. Jim aparece en acción y comenta: "así que tus amigos te han dejado solo". Freddie contesta: "Solo me distraen de esos momentos muertos. La oscuridad vuelve a aparecer". Jim responde: "Necesitas un amigo". "Me gustas. Ven a buscarme el día que te gustes a ti mismo" (01:00:35 - 01:03:04).
4.1. La soledad es un sentimiento muy extendido en nuestros días. Pero... ¿tal vez Freddie siempre se ha sentido así? ¿Cómo trata a sus gatos? ¿Sigue siendo el incomprendido que fundó Queen? ¿Qué puede hacerle sentir así? ¿Influye su inseguridad? ¿Qué opinas sobre ello?

¿Crees que Freddie estaba en lo cierto? ¿Qué te parece la fiesta que celebra? ¿Qué piensas tú de la lealtad? ¿Es leal quien te da la razón en todo? 0 ¿es más leal quien intenta hacerte ver los errores porque te aprecia? ¿Es fácil ser leales cuando estamos tan obcecados que no atendemos a razones?

4.2. El secreto de la felicidad no está en el dinero, sino en estar contento con uno mismo. ¿Crees que Freddie tendría baja su autoestima? ¿No actúa con prepotencia, con el "ego demasiado subido" porque sabe que es un artista excepcional? Reflexiona estas cuestiones. http://www.freddiemercury.com/es

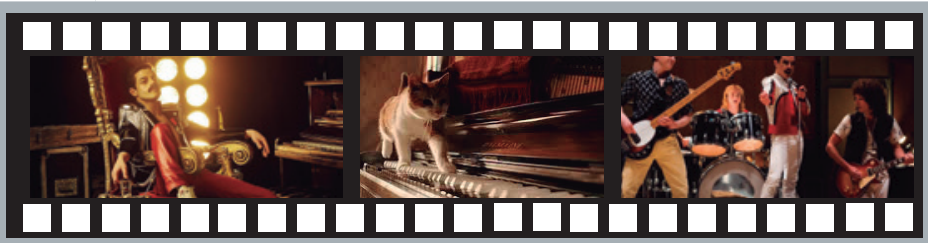

5.1. Tras la ruptura con Paul, Freddie siente que "necesita volver a la nave nodriza" (01:29:10 - 01:32:00). Se arrepiente de haber dejado su banda y se presenta diciendo: "Somos una familia. Las familias discuten. ¿Qué tendría que hacer para que me perdonaseis? Os necesito y vosotros a mí" (01:33:17 - 01:33:47) (01:34:20 - 01:37:42).

5.2. Terminando uno de los ensayos para el concierto Live Aid, Freddie exclama: "Lo he cogido. El SIDA. Quería que os enteraseis por mí. Lo siento. Que no salga de aquí". Y ante la posibilidad de que alguien sienta compasión, continúa: “Hacer música. Es lo que quiero hacer, no perder el tiempo. Me convertiré en un intérprete que dé a su público lo que desea: tocar el cielo. Lo que estaba destinado a ser". Uno de sus compañeros contesta: "Eres una leyenda" (01:41:49-01:44:40).
5.1. Dice el refrán: "amores reñidos, los más queridos". La convivencia es difícil. Hace falta mucha humildad para pedir perdón y mucho amor para aceptarlo. Discute sobre la pretensión de Freddie de volver al grupo y la reacción de Queen ante tal propósito.

5.2. En 1985 no se conocían muy bien los mecanismos sobre la transmisión del SIDA. Muchos enfermos eran rechazados por sus familias y sus amistades. ¿Cuál es la respuesta de los miembros del grupo? Freddie sabe que va a morir, que su enfermedad no tiene remedio. Siempre ha querido preservar su vida privada, a pesar del gran interés de los medios de comunicación. ¿Cómo valora y siente ahora la vida? Comenta su actitud ante la muerte. 


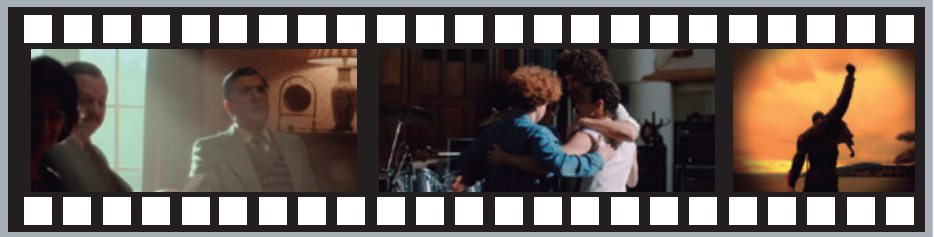

6.1. Esta expresión es un mantra que se ve en toda la película, referida siempre a la relación paternofilial, que no ha sido fácil. Frente a la comprensión de su madre y hermana.

6.2. Antes del concierto en Wembley, Freddie aparece en casa de sus padres con Jim que lo presenta como su amigo. ¿Qué ha cambiado desde el día que se conocieron? ¿Cómo se muestran su madre y hermana? Reflexiona sobre la actitud de su padre (01:46:14 - 01:48:10).
6.1. ¿Qué es lo que ha cambiado en la relación padre-hijo desde el principio hasta el final de la película? ¿Cuál crees que es la razón de ese cambio?

6.2. ¿Qué valores apreciamos en el abrazo entre padre e hijo? ¿Expresa qué sentimientos han aflorado ante esta secuencia? Parece que Freddie, al final de su vida, consiguió cumplir el mantra. Pero... ¿qué dices de la actuación de Mary, Jim y la banda?

\section{Aleunas curiosidades de interés}

1. ¿Sabíais que veintiocho años después de la muerte de Freddie Mercury, el 24 de noviembre de 1991, Queen fue la búsqueda top en Google en el año 2018?

2. Que Bohemian Rhapsody fue la canción con más búsquedas en 2018.

3. Que el actor que encarna a Freddie Mercury, Rami Malek, aceptó gustoso el papel. Primero estudió a fondo a esta leyenda del rock como ser humano, después abordó la música.

4. Que Roger Taylor ha sido elegido en 2018 el mejor baterista de rock a través de una encuesta de Rhythm/MusicRadar.

5. Que Bohemian Rhapsody se ha convertido en 2018 en la canción del siglo XX más escuchada en streaming.

6. Que el libro oficial de la película es Bohemian Rhapsody. The inside history realizado por $20^{\text {th }}$ Century Fox, publicado el 4 de octubre de 2018. El autor ha entrevistado a algunos de los intérpretes y equipo para escribir la asombrosa historia de Mercury y Queen llevada a la gran pantalla.

7. Que gracias al éxito del álbum A night at the Opera, en 1975, Queen recibió su primer disco de platino.

8. Que la genial actuación de Queen en Live Aid, el 13 de julio de 1985, se eligió como el mejor concierto de rock de todos los tiempos, veinte minutos inolvidables. https://elpais.com/elpais/2015/07/20/icon/1437385290_644340.html

9. Que Freddie Mercury admiraba a Monserrat Caballé, cantó a Barcelona, cuya letra relata el momento en que se conocieron. Juntos interpretaron el tema en varias ocasiones, pero no fue posible en la inauguración de los Juegos Olímpicos de 1992 a causa de la muerte de Mercury. https://www.youtube.com/watch?v=pHkrvwXX4sg

\section{Actividades de ekperiencia, reflekiôn y acción en común}

Reflexionamos sobre actitudes sociales ante la homosexualidad: Hasta hace muy pocos años, en nuestras sociedades había una intolerancia absoluta hacia la homosexualidad. Se consideraba que las personas, por naturaleza, debemos ser todas heterosexuales pues lo exige la continuidad de nuestra especie. Por lo tanto, la homosexualidad era una desviación que era necesario corregir, sobre todo en las primeras etapas de la vida 0, como tarde, en la adolescencia y juventud. Y para ello, en algunos casos, se ha sometido a estas personas a tratamientos y prácticas de las que derivaban sufrimientos y problemas psicológicos. La homosexualidad no solo estaba perseguida por las leyes con severas penas, sino que además las personas homosexuales eran objeto de toda clase de chistes y burlas; se les designaba con palabras despectivas y auténticos insultos; no era extraño que fueran vejados y golpeados en público; se suponía que eran personas viciosas, depravadas; y se les privaba de acceder a muchos empleos y a la vida social en general.

En esta situación, era lógico que disimulasen su condición e incluso que algunas personas aparentasen ser heterosexuales; incluso que se casasen con una persona del otro sexo y fundasen una familia. Era también frecuente que recurriesen a clubs, locales, discotecas... a las que solo solían acudir homosexuales.

Poco a poco se ha ido avanzando hacia la tolerancia y el respeto. En la actualidad, cada vez en más sociedades se considera que son perso- nas tan dignas y valiosas como cualquier otra persona: la inclinación sexual —hacia personas de otro sexo o del mismo — no implica mayor o menor valía y, por supuesto, todas las personas han de tener reconocidos los mismos derechos.

Con todo, los cambios sociales no son homogéneos. Hay personas a las que les cuesta admitir algo que es totalmente contrario a lo que han vivido durante toda su vida y que forma parte de su mentalidad y valores. En cambio, se diría que otras quieren compensar las injusticias que se han dado y propugnarían una especie de exaltación de la homosexualidad. En este sentido, hay personas a quienes les molesta la Ilamativa celebración del Día del Orgullo LGTB (lesbianas, gais, transexuales y bisexuales). Muchos de sus participantes aprovechan ese día para manifestarse de forma estruendosa y hasta provocativa, como un modo de reivindicar el derecho a vivir en público su forma de ser en contra de la intolerancia y la persecución que durante tanto tiempo han sufrido. Con todo, cabe pensar que, a medida que se normalice la aceptación de la homosexualidad, tendrán menos sentido celebraciones de estas características.

Una vez leídas y meditadas estas reflexiones, indagamos sobre ellas; asimismo, consideramos las diversas referencias citadas en esta guía y las relacionamos con la película. Por último, elaboramos una valoración personal que expondremos en grupo. 